\title{
The effect of regional changes in anthropogenic aerosols on rainfall of the East Asian Summer Monsoon
}

\author{
L. Guo ${ }^{1}$, E. J. Highwood ${ }^{1}$, L. C. Shaffrey ${ }^{2}$, and A. G. Turner ${ }^{2}$ \\ ${ }^{1}$ Department of Meteorology, University of Reading, Reading, UK \\ ${ }^{2}$ NCAS-Climate, University of Reading, Reading, UK \\ Correspondence to: L. Guo (1.guo@ reading.ac.uk) \\ Received: 31 July 2012 - Published in Atmos. Chem. Phys. Discuss.: 5 September 2012 \\ Revised: 7 January 2013 - Accepted: 26 January 2013 - Published: 6 February 2013
}

\begin{abstract}
The response of East Asian Summer Monsoon (EASM) precipitation to long term changes in regional anthropogenic aerosols (sulphate and black carbon) is explored in an atmospheric general circulation model, the atmospheric component of the UK High-Resolution Global Environment Model v1.2 (HiGAM). Separately, sulphur dioxide $\left(\mathrm{SO}_{2}\right)$ and black carbon (BC) emissions in 1950 and 2000 over East Asia are used to drive model simulations, while emissions are kept constant at year 2000 level outside this region. The response of the EASM is examined by comparing simulations driven by aerosol emissions representative of 1950 and 2000. The aerosol radiative effects are also determined using an off-line radiative transfer model. During June, July and August, the EASM was not significantly changed as either $\mathrm{SO}_{2}$ or BC emissions increased from 1950 to $2000 \mathrm{lev}$ els. However, in September, precipitation is significantly decreased by $26.4 \%$ for sulphate aerosol and $14.6 \%$ for black carbon when emissions are at the 2000 level. Over $80 \%$ of the decrease is attributed to changes in convective precipitation. The cooler land surface temperature over China in September $\left(0.8^{\circ} \mathrm{C}\right.$ for sulphate and $0.5^{\circ} \mathrm{C}$ for black carbon) due to increased aerosols reduces the surface thermal contrast that supports the EASM circulation. However, mechanisms causing the surface temperature decrease in September are different between sulphate and BC experiments. In the sulphate experiment, the sulphate direct and the 1st indirect radiative effects contribute to the surface cooling. In the $\mathrm{BC}$ experiment, the $\mathrm{BC}$ direct effect is the main driver of the surface cooling, however, a decrease in low cloud cover due to the increased heating by $\mathrm{BC}$ absorption partially counteracts the direct effect. This results in a weaker land surface temperature response to $\mathrm{BC}$ changes than to sulphate changes.
\end{abstract}

The resulting precipitation response is also weaker, and the responses of the monsoon circulation are different for sulphate and black carbon experiments. This study demonstrates a mechanism that links regional aerosol emission changes to the precipitation changes of the EASM, and it could be applied to help understand the future changes in EASM precipitation in CMIP5 simulations.

\section{Introduction}

Monsoons play a key role in global mass and heat transport (Trenberth et al., 2000). The Asian monsoon (including both the Indian monsoon and East Asian monsoons) is the strongest monsoon system due to the combination of thermal contrast between the largest continent and the Pacific and Indian Oceans and the presence of the highest terrain (Wang and Ding, 2006). It affects the lives of more than a third of the world's population in South and East Asia.

Over the past several decades, rapid industrialisation over Asia has resulted in a dramatic increase in emissions of aerosols and aerosol precursor gases (Smith et al., 2004; Nozawa et al., 2007). Aerosols have the potential to affect precipitation by modulating radiation in the atmosphere and at the surface (Haywood and Boucher, 2000) and by changing cloud microphysics (Twomey, 1977; Albrecht, 1989).

In recognition of the need to understand the variability of the monsoon and the industrialisation mentioned above, there have been a number of studies concerning aerosol and monsoon interaction in the past decade. Early studies considered only scattering aerosol, like sulphate (e.g. Boucher et al., 1998; Iwasaki and Kitagawa, 1998). An increase in scattering 
aerosols results in a negative direct radiative forcing at the top of the atmosphere (TOA), which reduces the short-wave radiation reaching the surface (also called "solar dimming") and acts to cool the global surface temperature. During summer, the land-sea surface temperature gradient over India is weakened in the presence of sulphate aerosol. Since the monsoon is driven by thermal contrast between continent and ocean, any weakening of this would weaken the monsoon circulation and decrease precipitation. Even though different models and methods are used in different studies, the result that increased sulphate aerosol suppresses monsoon circulation and decreases precipitation over South and East Asia is a consistent conclusion (Boucher et al., 1998; Iwasaki and Kitagawa, 1998; Huang et al., 2007; Randles and Ramaswamy, 2008). In those transient climate change simulations which consider sulphate, the cooling effects of sulphate are found to partially counteract the effects of increased carbon dioxide on monsoon precipitation (e.g. Roeckner et al., 1999; Ashrit et al., 2003; Johns et al., 2003).

The role of carbonaceous aerosols in absorbing short-wave radiation over South Asia and the north Indian Ocean [the Asian Blown Cloud (ABC)] was identified by Ramanathan et al. (2001). Subsequently, many researchers began to consider the mechanisms by which absorbing aerosol affects the monsoons over South and East Asia (Menon et al., 2002; Chung and Zhang, 2004; Chung and Ramanathan, 2006; Ramanathan et al., 2005; Lau et al., 2006; Wang, 2007; Meehl et al., 2008; Randles and Ramaswamy, 2008; Ming et al., 2010). Most of these studies are based on GCM simulations which compare the results of experiments with and without aerosol effects. However, unlike the consistent results for sulphate aerosol, the results of black carbon (BC) studies are diverse. In particular, the results appear to differ depending on whether an atmosphere-only model or a coupled oceanatmosphere model is used. In coupled models, the Indian monsoon is weakened as the meridional sea surface temperature (SST) gradient over the north Indian Ocean is reduced by surface cooling caused by the increased BC (Ramanathan et al., 2005; Meehl et al., 2008). However, in atmosphereonly models, BC increases the precipitation over Indian subcontinent during summer monsoon season (JJA) because the ascent is intensified by atmospheric heating due to the increased BC concentration (Menon et al., 2002; Randles and Ramaswamy, 2008). Chung and Ramanathan (2006) compared the relative importance of the weakening meridional SST gradient over the northern Indian Ocean and the atmospheric heating due to BC. They concluded that the precipitation patterns were opposite for the two cases and that the weakening meridional SST gradient over the northern Indian Ocean dominated the precipitation pattern.

The above mentioned studies of impacts have focused on the Indian monsoon; so far there are far fewer studies focusing on East Asia. Those that do exist (e.g. Wang, 2007; Kim et al., 2007; Lau et al., 2006) have drawn different conclusions as to impacts of aerosol (both sulphate and BC) on the East Asian monsoon based on modelling studies. For example, Wang (2007) suggested that the BC heating in a few specific areas such as the east and the west Pacific regions can have a remote impact on the East Asian Summer Monsoon (EASM) by causing an "ENSO-like" effect on the atmospheric circulation. Kim et al. (2007) suggested that the direct effect globally increased sulphate emissions induces changes in the north Pacific storm track during boreal spring, which in turn changes circulation and reduces rainfall over central East Asia. Lau et al. (2006) suggested that rainfall is suppressed over East Asia as a result of large-scale sea level pressure anomaly, itself induced by the enhanced rainfall anomally over India which is caused by the "elevated heat pump" mechanism. These proposed mechanisms are largescale and not necessarily related to local aerosol change in the East Asian monsoon region, which is in contrast to the studies of the aerosol impact on the Indian monsoon. In this study, we will focus on whether local changes in aerosol can affect the EASM.

It is important to note that GCM simulations studies (e.g. Boer and Yu, 2003) suggest that the regional pattern of temperature response to a particular forcing cannot be mapped directly from the regional pattern of forcing. Changes in temperature and other fields seen in East Asia may therefore be influenced by changes to radiation and clouds in remote locations. However, in this study, both the global aerosol impacts and global responses of surface temperature have been examined and seem to be small outside the region in which aerosol emissions are changed (East Asia), therefore, discussion will focus on the regional changes over East Asia.

Experiments for sulphate and BC aerosols are carried out separately. The model descriptions and experimental design are given in Sect. 2. The changes in aerosol concentration and cloud properties are given in Sect. 3. The responses of the EASM in surface temperature, precipitation and circulation to sulphate and BC are given in Sect. 4. Conclusions and discussions are given in Sect. 5.

\section{Models and Experiments}

\subsection{Models}

\subsubsection{HiGAM}

The general circulation model used in this study is the atmospheric component of the UK High-resolution Global Environment Model (HiGAM), version 1.2 (Shaffrey et al., 2009). The horizontal resolution of HiGAM is $0.83^{\circ}$ latitude $\times 1.25^{\circ}$ longitude; vertically HiGAM has 38 levels and the top of the atmosphere is $39 \mathrm{~km}$. HiGAM uses a non-hydrostatic, fully compressible dynamical core, with semi-Lagrangian advection. It is discretized horizontally on the Arakawa C-grid and vertically on the Charney-Phillips staggered grid (Davies et al., 2005). The 

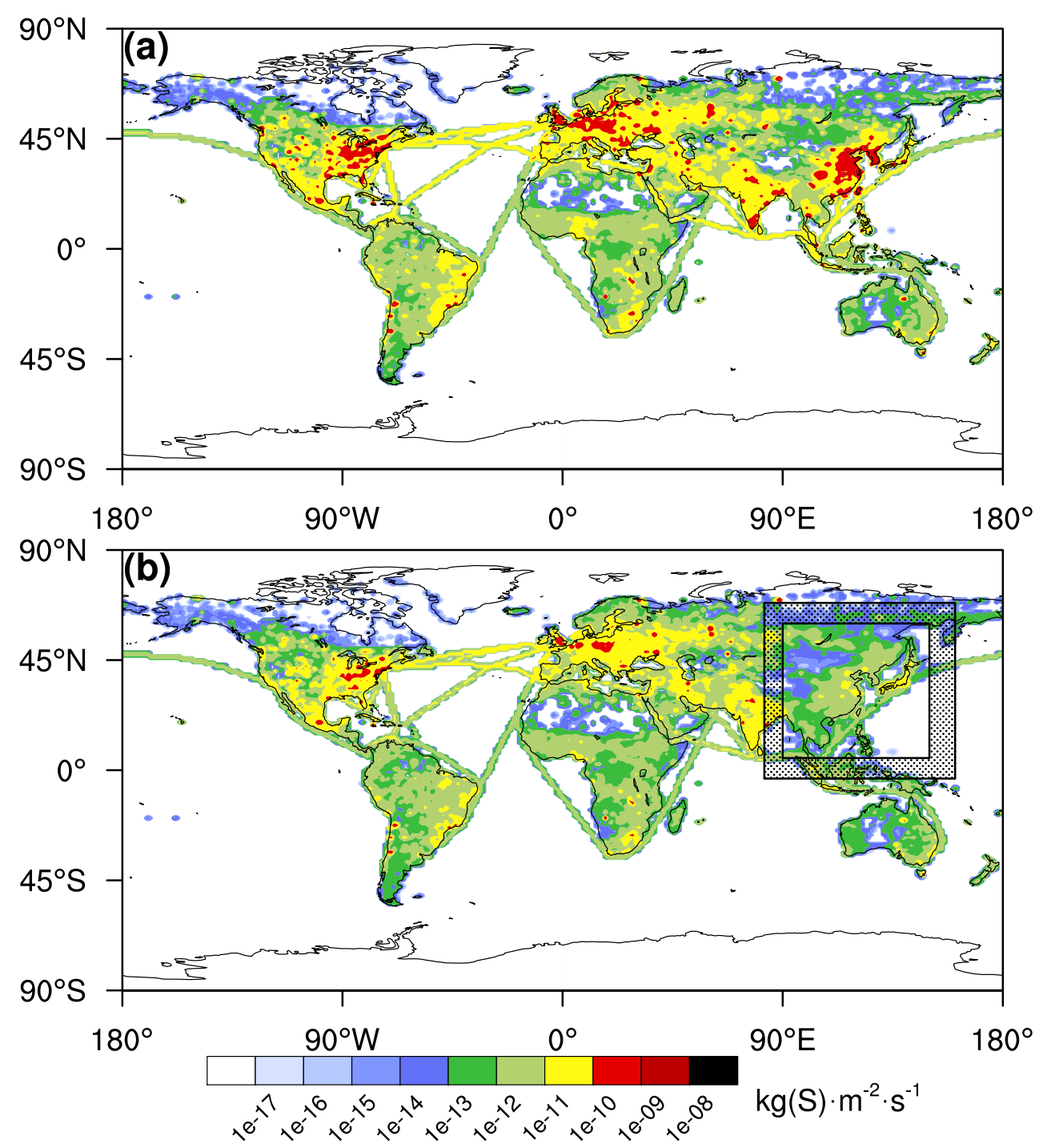

Fig. 1. Annual mean $\mathrm{SO}_{2}$ emissions. Units: $\operatorname{kg}(\mathrm{S}) \mathrm{m}^{-2} \mathrm{~s}^{-1}$. (a) Emissions in 2000. (b) Same as (a), except that, within the inner box (5$60^{\circ} \mathrm{N}, 90-150^{\circ} \mathrm{E}$ ), the emissions are in the level of 1950. A linear transition is applied between inner and outer boxes. Emission data is from Smith et al. (2004).

physical parametrisations in HiGAM are similar to those in HadGAM1 (Hadley Centre Global Environmental Model, with horizontal resolution of $1.25^{\circ}$ latitude $\times 1.875^{\circ}$ longitude) which has been summarised by Martin et al. (2006). Performance of the coupled version of HiGAM has been evaluated by Shaffrey et al. (2009), in which they noted that the higher resolution decreases SST errors, improves small scale coupling and the simulation of ENSO.

The precipitation in HiGAM is parameterized separately as convective precipitation and large-scale precipitation. The parameterization of large-scale precipitation together with large-scale cloud are originally described by Smith (1990). The cloud water content and cloud amount are calculated from specific total water content and the saturated specific humidity using a symmetric triangular probability distribu- tion function. The precipitation is depleted from cloud water as soon as cloud water is condensed. The microphysical process is considered and represented differently for liquid clouds and ice clouds. The auto-conversion rate of cloud water to rain water in liquid clouds is linked to the cloud condensation nuclei (CCN). However, since less $\mathrm{CCN}$ act as ice nuclei (IN), the representation of precipitation of ice cloud use a constant value which is not link to IN. The convection scheme is based the mass flux scheme originally developed by Gregory and Rowntree (1990) with a modification to explicitly couple it to the boundary layer scheme. Unlike largescale precipitaiton, in HiGAM, the aerosol cannot change convective precipitation microphysically.

There are four types of aerosol species included in HiGAM: sulphate, black carbon, biomass burning material 
and sea salt. Biomass burning maerial is defined as the mixture of black carbon and other organic materials. Sulphur dioxide ( $\mathrm{SO}_{2}$, a precusor gas for sulphate) and $\mathrm{BC}$ are two major anthropogenic aerosol sources over East Asia (see Fig. 1a and Fig. S6). Biomass burning aerosol is mainly emitted from Southeast Asia and southern hemispherical continent (see Fig. S7). Organic aerosol is only represented in this model as a component of biomass burning aerosol. We anticipate that the missing organic and nitrate aerosol likely emitted from similar sources to the sulphate pre-cursors leads to our results being a slight underestimate of the radiative impact of total scattering aerosol components. However, we concerntrate on $\mathrm{SO}_{2}$ and $\mathrm{BC}$ as the likely major contributors to an aerosol effect in this region.

Figure 1a shows the annual mean emissions of $\mathrm{SO}_{2}$ in 2000 (data from Smith et al., 2004). East Asia (defined here as $5-60^{\circ} \mathrm{N}, 90-150^{\circ} \mathrm{E}$ ) is one of the three strongest emission regions in the world, the annual mean emission intensity being about $39.5 \mathrm{Tg}\left(\mathrm{SO}_{2}\right) \mathrm{yr}^{-1}$; the other two important regions are Western Europe and the east coast of USA. Compared to the other two regions, East Asia has been a rapidly industrialising region since the 1950s, the increase of emissions has been dramatic. According to the historical emission data from Smith et al. (2004), in 1950 over East Asia the annual mean emission intensity of $\mathrm{SO}_{2}$ was $3.5 \mathrm{Tg}\left(\mathrm{SO}_{2}\right) \mathrm{yr}^{-1}$; since then, the emissions of $\mathrm{SO}_{2}$ have been increased by ten-fold in the second half of the twentieth century. However, over the other two intensive emission regions, the peaks of emissions appeared during the 1970s, and were twice the magnitude of emissions in 1950. BC emissions have a similar geographical pattern as $\mathrm{SO}_{2}$, as both of them are primarily emitted from fossil fuel burning due to anthropogenic activities. According to historical emission data from Nozawa et al. (2007), the annual emission intensity of BC over East Asia in 1950 was $0.3 \mathrm{Tg}(\mathrm{C}) \mathrm{yr}^{-1}$, which increased to $2.4 \mathrm{Tg}(\mathrm{C}) \mathrm{yr}^{-1}$ by 2000 .

The sulphate scheme is described by Jones et al. (2001) and Woodage et al. (2003), in which the precursor gases $\left(\mathrm{SO}_{2}\right)$ and dimethyl sulphate $\left(\left(\mathrm{CH}_{3}\right)_{2} \mathrm{SO}_{4}\right)$ undergo chemical reactions with oxidants in the atmosphere to form sulphate aerosols in both gaseous (with hydroxyl, $\mathrm{OH}$ ) and aqueous (with hydrogen peroxide, $\mathrm{H}_{2} \mathrm{O}_{2}$ ) phases. The oxdiant fields are kept constant in HiGAM. They are monthly 3-D fields, produced from simulations using the Lagrangian chemistry model STOCHEM (Collins et al., 1997; Stevenson et al., 1997). In HiGAM, sulphate aerosols are treated as hydrophilic and can therefore act as cloud condensation nuclei $(\mathrm{CCN})$. Thus a change in sulphate aerosols can lead to changes in cloud reflectivity and lifetime through changes in the cloud droplet number concentration (CDNC). Sulphate aerosols are assumed to be in one of three different size modes: Aitken mode (median radius $\mathrm{r}_{\mathrm{Ait}}=24 \times 10^{-9} \mathrm{~m}$ and geometric standard deviation $\sigma=1.45$ ), accumulation mode $\left(\mathrm{r}_{\mathrm{acc}}=95 \times 10^{-9} \mathrm{~m}\right.$ and $\left.\sigma=1.4\right)$ and dissolved mode (sulphate dissolved in cloud water droplets). The optical properties (single scattering albedo, mass extinction coefficient and asymmetric function) of the Aitken mode and accumulation mode vary with relative humidity, whilst there are no separately defined optical properties for dissolved mode as it is part of cloud water droplet. The optical properties as a function of relative humidity and wavelength are shown as Fig. S2 and S3 in the supplemental information. The black carbon (BC) scheme (Roberts and Jones, 2004) is different in that BC is assumed emitted as primary particles. BC emissions from surface are initially described as a "fresh mode". Two other two black carbon modes exist in the model, "aged mode" and "dissolved black carbon" in cloud droplets. Both the fresh mode and aged mode are assumed to have the same lognormal size distributions, with median radius $r=$ $40 \times 10^{-9} \mathrm{~m}$ and geometric standard deviation $\sigma=2.0$. The fresh mode is however, hydrophobic whilst the aged mode has optical properties representative of an internal mixture of black carbon particles with hydrophilic material. The BC is treated as insufficiently soluble to act as $\mathrm{CCN}$ in the model. Therefore, the optical properties of $\mathrm{BC}$ are not sensitive to relative humidity. Finally, some aged black carbon becomes internally mixed with cloud water, forming dissolved black carbon in cloud droplets. The optical properties of black carbon used in this paper are shown in Fig. S4 in the supplement.

\subsubsection{Edwards-Slingo radiative transfer model}

An off-line radiative transfer model is also used in this work to estimate aerosol radiative effects. This is the same radiation scheme used in HiGAM. This model was first introduced by Edwards and Slingo (1996) (E-S code hereafter) and it calculates radiative fluxes by summing the results of a number of quasi-monochromatic fluxes, each carried out using a two-stream approximation.

To estimate the aerosol radiative effect in HiGAM, the single column version of E-S code has been expanded into a 3dimensional version. The atmospheric state variables (temperature, pressure and relative humidity), various radiative agents (greenhouse gases, aerosols and clouds) on each grid point are taken from the monthly mean output of HiGAM. Myhre et al. (2002) pointed out that calculation of the radiative effect is sensitive to spatial and temporal resolution. The coarser the resolution, the more underestimated the radiative effect will be. The coarser resolution averages and smooths out the small scale relative humidity fluctuations, as sulphate optical properties increase non-linearly with relative humidity, the sulphate radiative effect estimated using smoothed relative huditity is smaller than the estimates with high value small scale relative humidity fluctuations. The aerosol radiative effects shown here use the monthly output of HiGAM. Therefore, the magnitude is likely to be underestimated, but it can still be used qualitatively to explain the different impacts from different aerosol species.

The definition of the aerosol radiative effect in this study is similar to the definition of aerosol radiative forcing in other studies, including the IPCC report (e.g., Forster et al., 2007; 
Haywood and Shine, 1997). However, there are two differences between the effect used in this study and the forcing in others. Temporally, the radiative effect refers to the change in monthly (or even shorter time interval) net radiation rather than annual mean. Spatially, the radiative effect is a regional estimate over East Asia rather than global mean.

Three different aerosol radiative effects have been calculated in this study using the E-S code. The "direct radiative effect", is calculated as the difference of net radiation at both TOA and surface due to the change in sulphate or BC concentration, but with the atmospheric state variables (temperature, pressure and relative humidity) and other radiative agents unchanged. The "combined radiative effect" of direct and first indirect effect for sulphate aerosol, is calculated from the difference of the net radiation at both TOA and surface by considering changes in both sulphate concentration and cloud droplet size predicted by the model. The "combined radiative effect" of direct and semi-direct effect for BC aerosol, is calculate the difference of the net radiation at both TOA and surface by considering changes in both $\mathrm{BC}$ concentration and in cloud cover change. Note that, since the changes in cloud cover and cloud liquid water content are not significant in sulphate experiment, only changes in cloud droplet size are considered in the off-line model. And since BC aerosol cannot act as $\mathrm{CCN}$, there is no indirect effect considered in $\mathrm{BC}$ experiment. More details will be mentioned in the following text.

\subsection{Experiment design}

The experiments in this study are designed to explore impacts of aerosol on the EASM. Three experiments are carried out (see Table 1). In the Control experiment, global emissions of both $\mathrm{SO}_{2}$ and $\mathrm{BC}$ are used at the 2000 level. Sea surface temperature and sea ice data are from AMIP-II (http: //www-pcmdi.llnl.gov/projects/amip/), greenhouse gases except ozone are given as fixed values, while ozone uses the time series of the Stratospheric Processes and Their Role in Climate (SPARC) program. More details of model configuration can be found in Martin et al. (2006); Shaffrey et al. (2009). In the $\mathrm{SO}_{2-1} 1950$ experiment, $\mathrm{SO}_{2}$ emissions at the 1950 level are used over East Asia $\left(5-60^{\circ} \mathrm{N}, 90-150^{\circ} \mathrm{E}\right)$, but $\mathrm{SO}_{2}$ emissions are kept at 2000 level over the rest of the world (as shown in Fig. 1b). In the BC_1950 experiment, BC emissions at the 1950 level are used over East Asia, while those over the rest of world are at the 2000 level. The Control experiment is an eighteen-year AMIP-type run (Gates et al., 1999), driven by observed monthly mean SST from 1983 to 2000. The $\mathrm{SO}_{2} \_1950$ and BC_1950 simulations consist of an 18 member ensembles of the period April to September, beginning in each April of the control run. The validity of this experimental design is based on the fact that the lifetimes of both sulphate and BC aerosols are short. In HiGAM, the global mean lifetime of sulphate is four days and it is six days for BC. Aerosol concentration in the atmosphere ad-
Table 1. Summary of aerosol emissions used in experiments. East Asia is defined as a region of $5-60^{\circ} \mathrm{N}, 90-150^{\circ} \mathrm{E}$. In $\mathrm{SO}_{2-1950}$ experiment, $\mathrm{BC}$ emissions are same as Control experiment. In BC_1950 experiment, $\mathrm{SO}_{2}$ emissions are same as Control experiment.

\begin{tabular}{lll}
\hline Experiment & $\begin{array}{l}\text { Aerosol Emissions } \\
\text { over East Asia }\end{array}$ & $\begin{array}{l}\text { Aerosol Emissions } \\
\text { over rest of the world }\end{array}$ \\
\hline Control & $\mathrm{SO}_{2}$ in 2000 & $\mathrm{SO}_{2}$ in 2000 \\
$\mathrm{BO}_{2-1950}$ in 2000 & $\mathrm{SO}_{2}$ in 1950 & $\mathrm{BC}$ in 2000 \\
$\mathrm{BC}_{-} 1950$ & $\mathrm{BC}$ in 1950 & $\mathrm{SO}_{2}$ in 2000 \\
\hline
\end{tabular}

justs quickly to the change in emissions and long continuous runs are therefore not necessary.

\subsection{Evaluation of East Asian Summer Monsoon in HiGAM}

Figure $2 \mathrm{a}, \mathrm{b}$ and $\mathrm{c}$ compare the global JJA precipitation in HiGAM with the Globa Precipitation Climatology Project (GPCP) data version 2 (Adler et al., 2003). This dataset provides monthly data on a $2.5^{\circ} \times 2.5^{\circ}$ grid for the period of 1979-present. The $850 \mathrm{hPa}$ geopotential height and wind over East Asia compared to monthly ERA40 data (Uppala et al., 2005) are shown in Fig. 2d, e and f. HiGAM captures the global pattern of precipitation, and compared to models with lower horizontal resolution HiGAM enhances the precipitation over the coast the maritime continent and the southern slope of the Himalayas. However, over East Asia, the Meiyu/Baiyu/Changma front is weaker in HiGAM than in the observations, with an deficit also over India. Both these biases also exist in most of the CMIP3 and CMIP5 model participants (Sperber et al., 2012). The weak Meiyu/Baiyu/Changma front is a result of a weak subtropical high over the western North Pacific Ocean. The excessive rainfall in the maritime continent and the deficit in precipitation over India may be related to a circulation that is too zonal across the Asian monsoon domain. However, HiGAM captures the most prominent features of the EASM, the Somali jet over the northern Indian Ocean and the subtropical anticyclone over the western North Pacific Ocean.

Figure 3 compares the annual cycle of precipitation averaged between longitude $\left(107^{\circ}-122^{\circ} \mathrm{E}\right)$. One key characteristic of the EASM is the asymmetric propagation of monsoon precipitation with an abrupt monsoon onset at the end of the May and a gradual withdrawal to the end of September (Hung et al., 2004). As shown in Fig. 3, this asymmetry is well captured in HiGAM, except that the precipitation is stronger. In addition there is persistent precipitation over the southern China (between $20^{\circ}-30^{\circ} \mathrm{N}$ ) from February to May in both HiGAM and GPCP data. Tian and Yasunari (1992) refer to this as the Spring Persistent Rains over central China. The Spring Persistent Rains are caused by the 

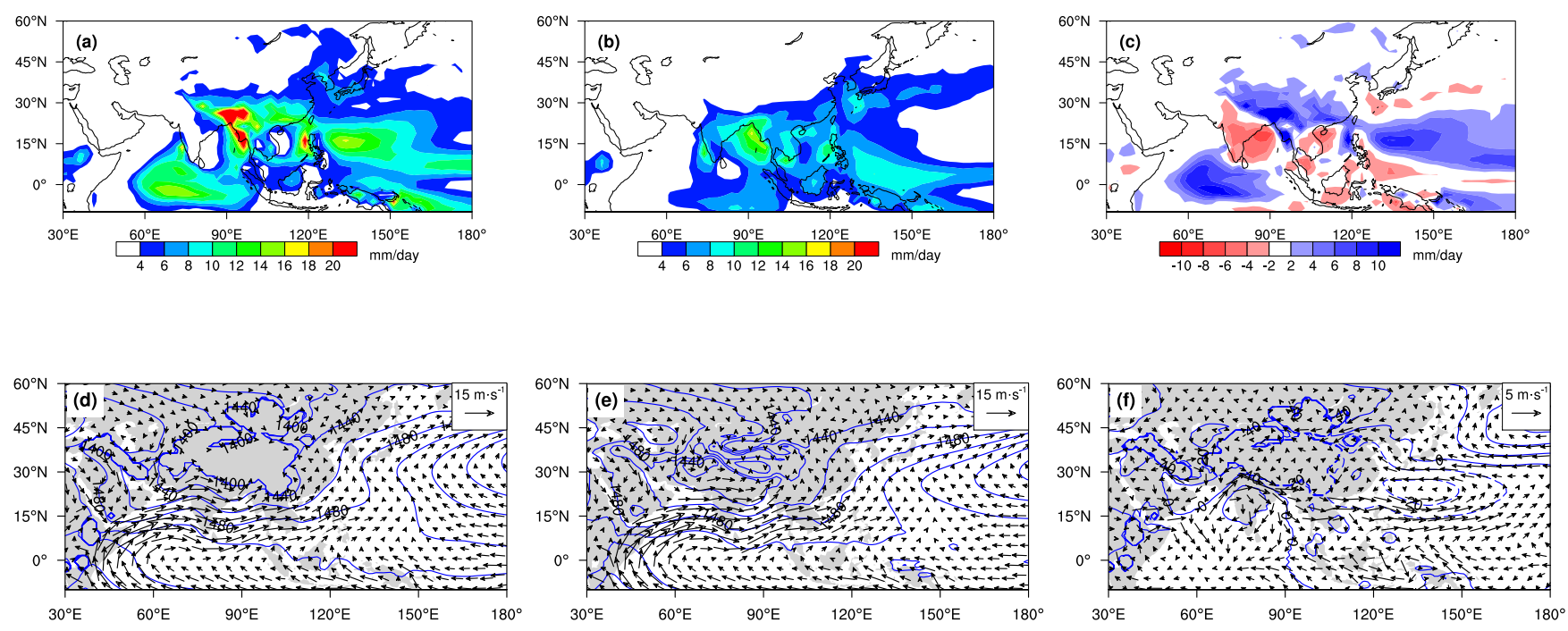

Fig. 2. (a) JJA precipitation in HiGAM (1983-2000, units: mm/day). (b) JJA precipitation from GPCP $2.5 \times 2.5$ monthly data (1983-2000, units: $\mathrm{mm}_{\text {day }}{ }^{-1}$ ). (c) Difference in JJA precipitation (HiGAM minus GPCP) during 1983-2000 (units: $\mathrm{mm} \mathrm{day}^{-1}$ ). (d) JJA 850 hPa geopotential height (contour, units: gpm) and wind (vector, units: $\mathrm{m} \mathrm{s}^{-1}$ ) in HiGMA (1983-2000). (e) JJA 850 hPa geopotential height (contour, units: gpm) and wind (vector, units: $\mathrm{m} \mathrm{s}^{-1}$ ) from ERA40 (1983-2000). (f) Difference in JJA $850 \mathrm{hPa}$ geopotential height and wind (HiGAM minus ERA40).
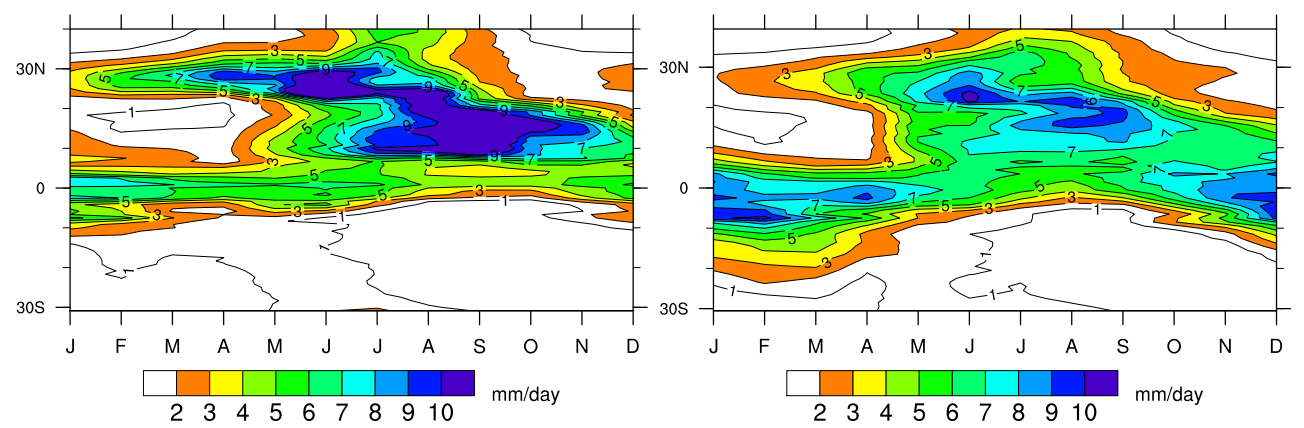

Fig. 3. Annual cycle of precipitation averaged between $107^{\circ}-122^{\circ}$ E. Units: mm day ${ }^{-1}$. (Left) HiGAM and (Right) GPCP.

interaction between low level flow and the orography over eastern China. Due to HiGAM's high horizontal resolution, the Spring Persistent Rains have been well captured compared to other models. Thus we believe that local and regional physical mechanisms are represented well in HiGAM although there may be some biases in the larger scale circulation pattern. Since we will be changing emissions on a regional basis, this model can be used, the biases not withstanding.

\section{Changes in aerosols and clouds}

Figure $4 \mathrm{a}$ shows eighteen-year monthly and area-mean aerosol column burdens for sulphate and black carbon over East Asia in Control, $\mathrm{SO}_{2-1} 1950$ and BC_1950 experiments. Due to the short lifetime and therefore the short adjustment time of aerosol concentration in HiGAM, monthly aerosol column burdens are different between the 1950 runs and the Control run soon after the start of the runs. The magnitudes of the column burden in 1950-emissions experiments are half of the magnitude in the Control experiment. However, as mentioned in Sect. 2, emissions in 1950 are a tenth of the magnitude of emissions in 2000. This difference between emissions and concentrations in the atmosphere indicates that the concentrations of aerosol in the atmosphere are also determined by transport, processing and deposition, and that these must also change in the 1950 experiments.

The column burden of sulphate (sum of Aitken mode and accumulation mode) in the Control run (the blue solid line in Fig. 4a) shows a clear seasonal variation, with higher column burden in the summer monsoon season (JJA) and lower values in the pre- and post-monsoon months. The higher column burden in JJA is likely due to more active photochemistry which produces more sulphate particles as the solar zenith 

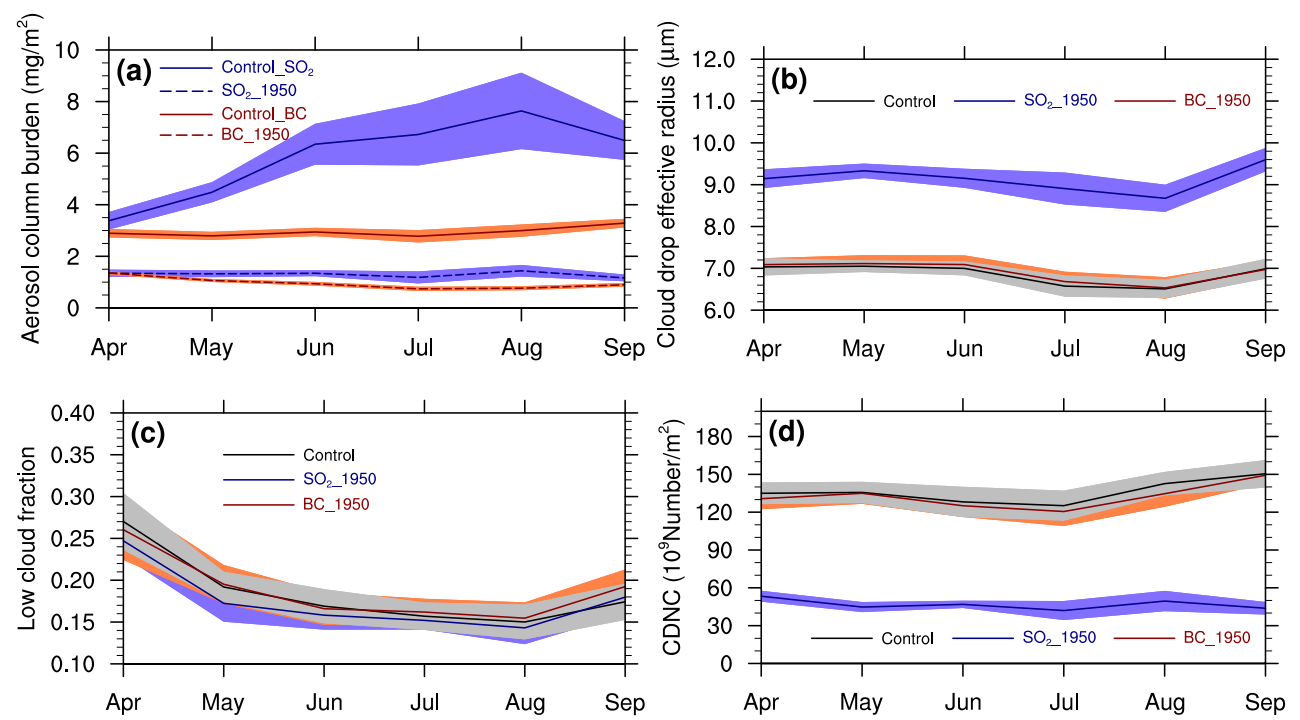

Fig. 4. (a) Eighteen-year (1983-2000) monthly and area-mean aerosol column burden over East Asia. Units: mg m ${ }^{-2}$. (b) Eighteen-year (1983-2000) monthly area-mean vertical mean cloud drop effective radius over East Asia. Units: $\mu$ m. (c) Eighteen-year (1983-2000) monthly and area-mean low cloud fraction over East Asia. Units: 1. (d) Eighteen-year (1983-2000) monthly and area-mean cloud droplet number concentration. Units: $10^{9}$ number $\mathrm{m}^{-2}$. Shading colours along each line are standard deviations calculated using eighteen-year monthly data.

angle is smaller. The seasonal variation of sulphate column burden in $\mathrm{SO}_{4-1950}$ experiment is much smaller. Thus, the difference of the column burden of sulphate between the Control experiment and $\mathrm{SO}_{2}-1950$ experiment is bigger in JJA.

Figure $4 \mathrm{~b}$ shows eighteen-year monthly area and verticalmean cloud droplet effective radius over East Asia in Control, $\mathrm{SO}_{2}$ 1950 and BC_1950 experiments. Sulphate particles can act as $\mathrm{CCN}$, and if we assume that cloud liquid water content is virtually unchanged, more $\mathrm{CCN}$ due to a higher sulphate concentration leads to smaller cloud drops, and vice versa (as shown in Fig. 4d). Therefore the size of cloud drop (represented by the cloud droplet effective radius $r_{e}$ ) should be anti-correlated with the concentration of sulphate in the atmosphere. The mean $\mathrm{r}_{\mathrm{e}}$ in the Control experiment $(7 \pm 0.2 \mu \mathrm{m})$ is smaller than in the $\mathrm{SO}_{2-1950}$ experiment $(9 \pm 0.3 \mu \mathrm{m})$. The cloud albedo is anti-correlated to cloud droplet size: smaller cloud drops make cloud more reflective. The radiation budgets at TOA and the surface are therefore sensitive to the changes in $\mathrm{r}_{\mathrm{e}}$, as we will discuss in more detail in Sect. 4.

However, the column burdens of black carbon in both Control and BC_1950 experiments do not show any clear seasonal variation (Fig. 4a). This is because BC emissions in HiGAM are derives from industries, therefore have no seasonal variation (BC emissions from biomass burning are small compared to from industrial emissions), also that $\mathrm{BC}$ is emitted as primary particles in HiGAM and its concentration depends more on physical conditions of the atmosphere rather than photochemistry. As $\mathrm{BC}$ cannot act as $\mathrm{CCN}$ in
HiGAM, changes of BC column burden hardly effect $r_{e}$ and cloud drops remain at a similar size to those in the Control experiment (Fig. 4b).

Since sources of anthropogenic emission are mainly confined to the surface, and the lifetimes of both sulphate and black carbon are short, the vertical distributions of sulphate and black carbon are uneven with larger concentrations confined within $2 \mathrm{~km}$ above the surface (See Fig. S5 in the Supplement). This vertical distribution of aerosols makes the aerosol indirect effect on low level cloud more important than other types of cloud, thus the strong aerosol-cloud interactions in HiGAM occur at the bottom of the atmosphere.

Figure $4 \mathrm{c}$ shows eighteen-year monthly and area-mean low cloud fraction over East Asia in the three experiments. A similar seasonal cycle can be observed in Fig. $4 \mathrm{c}$ for all the experiments. Low cloud fraction decreases from April, stays small during JJA, and increases again in September when the EASM withdraws from the region under consideration. Yu et al. (2004) suggested that the larger low cloud fraction (mainly stratus) in pre- and post-monsoon season are generated and maintained by the frictional and blocking effect of the Tibetan Plateau. During the summer monsoon season, as more active convection is occurring over East Asia, mid and high-level clouds are dominant. 

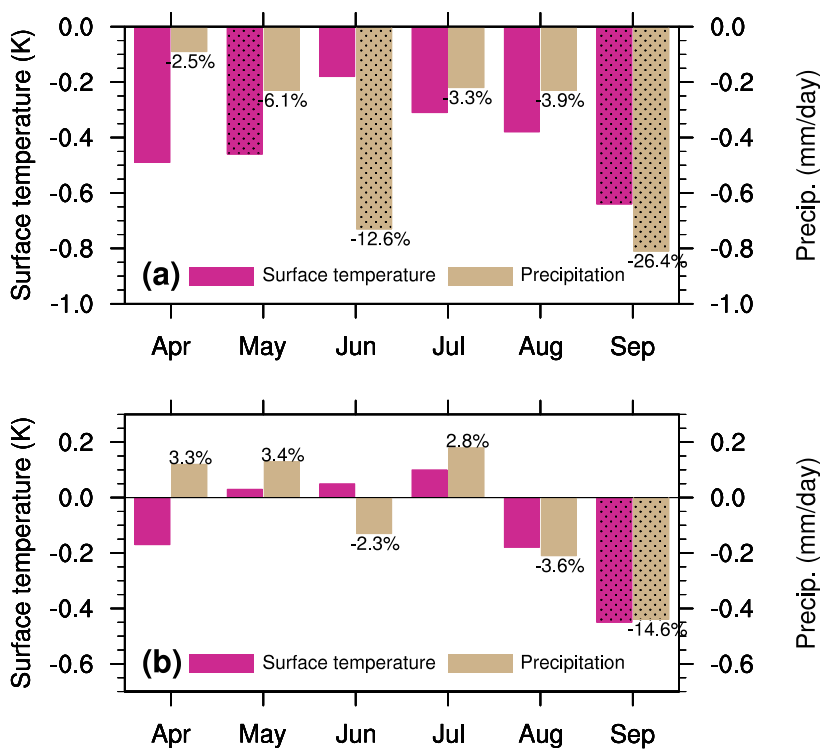

Fig. 5. Changes in monthly area mean surface temperature (red, units: $\mathrm{K}$ ) and precipitation (green, units: $\mathrm{mm} \mathrm{day}^{-1}$ ) over East Asia continent $\left(20-45^{\circ} \mathrm{N}, 100-122^{\circ} \mathrm{E}\right)$. (a) Change in sulphate experi-

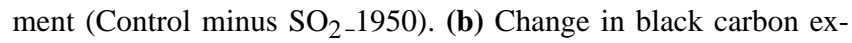
periment (Control minus BC_1950). The percentage over each precipitation bar is percentage changes of precipitation against Control experiment. Significant changes excess $95 \%$ confident level are hatched.

\section{Climate responses of the East Asian Summer Monsoon}

\subsection{Sulphate experiment}

Figure 5 shows the monthly change of surface temperature and precipitation averaged over East Asia; results are subjected to Student's t-test and changes exceeding $95 \%$ significance are hatched. As sulphate has increased (Fig. 5a), both surface temperature and precipitation decrease in each month (Control minus $\mathrm{SO}_{2}$ 1950). Significant decreases of surface temperature occur in May and September only, while significant decreases of precipitation occur in June and September only. The surface temperature decrease in May is due to the increased low cloud cover with smaller cloud droplet size which significantly increases reflectivity in the Control experiment. However, there is no corresponding significant decrease in precipitation in May, because the EASM has not yet advanced over this region. The small change in precipitation $\left(-0.2 \mathrm{~mm} \mathrm{day}^{-1}\right)$ is mainly due to changes in local evaporation $\left(-0.13 \mathrm{~mm} \mathrm{day}^{-1}\right.$, shown as Fig. S9). Precipitation in June has decreased significantly by nearly $13 \%$, however there is no corresponding significant decrease in surface temperature. The decrease of precipitation is distributed rather locally in June (not shown), and is mainly confined to southern China where the monsoon front is located. This decrease of precipitation in June indicates a delayed onset of the
EASM due to cooler land surface temperatures in May and a weaker monsoon onset. In September, both surface temperature and precipitation show the biggest decrease. However, as monsoon precipitation is dominated by convection, which could occur above the aerosol layer, and as monsoon precipitation has strong inter-annual variations, the impacts of aerosol in these experiments are not significant on the EASM during JJA. These changes in surface temperature and precipitation in each month are related to aerosol radiative effects.

The black lines in Fig. 6a and b show the monthly sulphate direct radiative effect at TOA and the surface averaged over East Asia $\left(20-45^{\circ} \mathrm{N}, 100-122^{\circ}\right.$ E). Sulphate exerts a negative radiative effect over East Asia as $\mathrm{SO}_{2}$ emissions increase from 1950 to 2000 . The magnitude of the sulphate direct radiative effects at TOA and the surface are comparable, as sulphate is a scattering aerosol and little radiative energy is absorbed in the atmosphere. As shown in Fig. 6a and $\mathrm{b}$, the negative radiative effect of sulphate is stronger during the summer monsoon season (JJA). This is consistent with the difference of sulphate column burden between the Control and $\mathrm{SO}_{2}-1950$ experiment (shown as the solid blue line and the dashed blue lines of Fig. 4a), and indicates that more sulphate in the atmosphere during JJA reflects more solar radiation back to space, and reduces the incident solar radiation at the surface. However, the sulphate direct radiative effect is small in September, so it would appear that this does not explain the stronger decreases in surface temperature and precipitation at that time.

The blue lines in Fig. 6a and b show the monthly sulphate combined radiative effect at TOA and the surface averaged over East Asia. When the decrease of cloud droplet size is taken into account, the negative radiative effect of sulphate is significantly intensified in April, May and September. The monthly variation of the sulphate combined radiative effect is similar to the variation of surface temperature and precipitation, especially in September, the stronger negative sulphate radiative effects being co-located with stronger cooling at the surface and the stronger reduction in precipitation. In general, the sulphate combined effect is larger than the sulphate direct effect. This is because with larger low cloud fraction in April and September over East Asia (as shown in Fig. 7), the sulphate-cloud interaction becomes important, especially in September.

Figure $8 \mathrm{a}$ shows the geographical distribution of the eighteen-year sulphate combined effect (all-sky) at the surface in September. It is negative over East Asia with the centre over the lee side of the Tibetan Plateau where low cloud fraction is large. This suggests an important role for indirect effect and additional off-line simulations changing only cloud properties show that the sulphate 1st indirect effect accounts for $66 \%\left(-2.11 \mathrm{Wm}^{-2}\right.$, see also Fig. S14) of the combined effect (all-sky).

Figure $8 \mathrm{~b}$ shows the eighteen-year mean changes in surface temperature in September due to sulphate increase (Control minus $\mathrm{SO}_{2}{ }_{1} 1950$ ). Surface temperature has a negative 

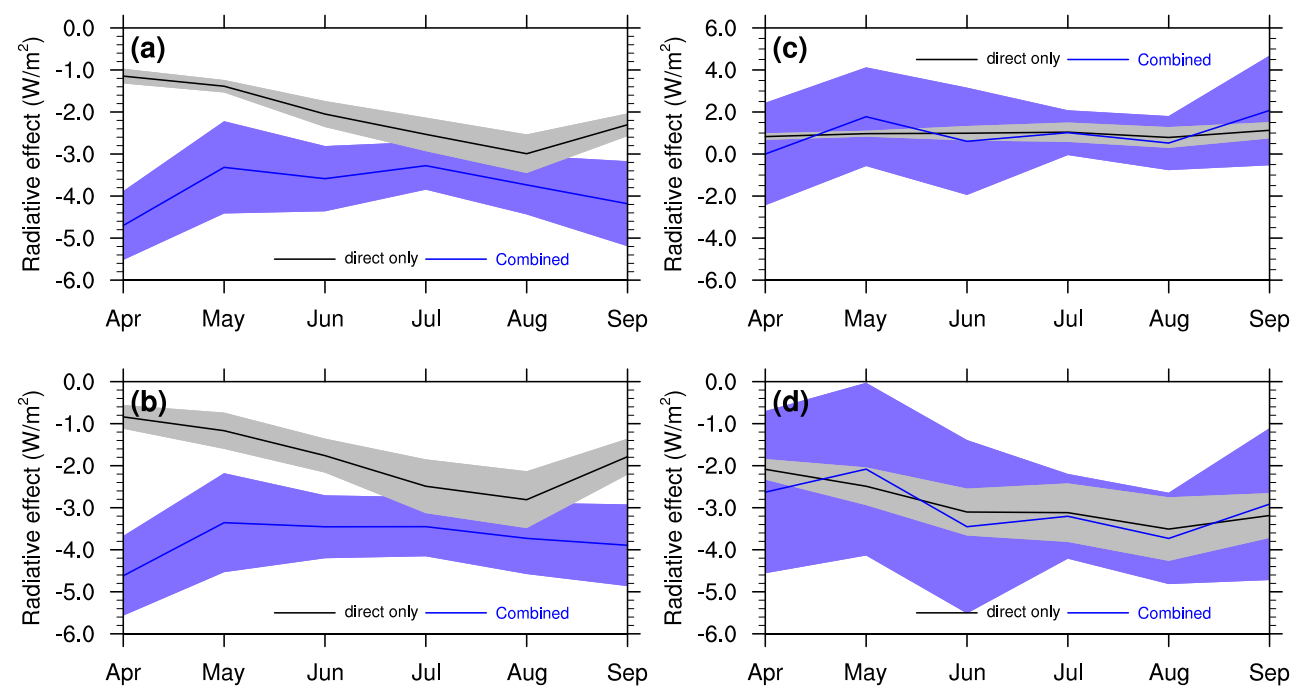

Fig. 6. (a) 18-yr monthly area-mean sulphate radiative effect (Control minus $\mathrm{SO}_{2-1950)}$ at $\mathrm{TOA}$ over East Asia $\left(20-45^{\circ} \mathrm{N}, 100-122^{\circ} \mathrm{E}\right)$. (b) Same as (a), but for surface. (c) 18-yr monthly area-mean black carbon radiative effect (Control minus $\left.\mathrm{SO}_{2}-1950\right)$ at TOA over East Asia. (d) Same as (c), but for surface. Units: $\mathrm{W} \mathrm{m}^{-2}$. Black line is direct-only effect, grey shading is standard deviation. Blue line is combined effect, blue shading is standard deviation.

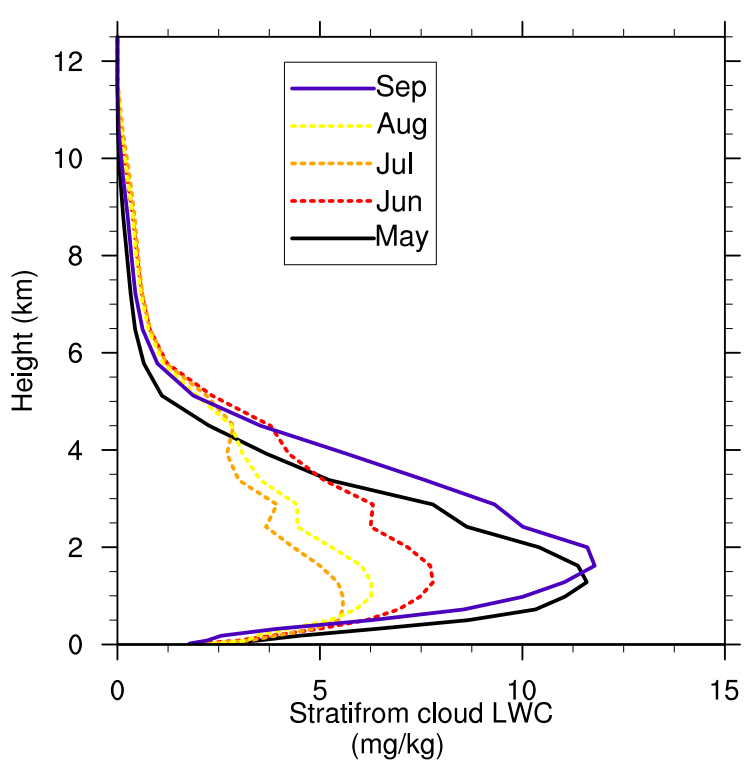

Fig. 7. Vertical profile of liquid water content of stratiform cloud in CONTROL experiment average $20-45^{\circ} \mathrm{N}, 100-122^{\circ} \mathrm{E}$.

change which is consistent with the sulphate combined effect at the surface. Surface temperature decreases over southeastern China, central China, the southern slopes of the Tibetan Plateau and parts of the Indochina Peninsula. Figure 8c shows the eighteen-year mean changes in precipitation in September (Control minus $\mathrm{SO}_{2-1}$ 1950). The precipitation significantly decreases over central China, south-western China and parts of the Indochina Peninsula. Since the change in precipitation over East Asia can be contributed to differ- ent factors rather than aerosol, e.g. ENSO, GHGs, it is unfair to compare this result with observation trend. However, Zhai et al. (2005) shows a generally decrease in precipitation throughout eastern China using daily precipitation date of 740 rain gauges.

There are two mechanisms that can be used to explain the decrease of precipitation over East Asia. One is that the local evaporation will decrease as the surface temperature decreases. However, the decrease of local evaporation in September $\left(-0.11 \mathrm{~mm} \mathrm{day}^{-1}\right.$ over East Asia) is too small to explain the precipitation decrease $\left(-0.82 \mathrm{~mm} \mathrm{day}^{-1}\right)$. Another explanation is that the change in surface temperature will induce changes in monsoon circulation. As the land surface temperature is decreased, the thermal contrast between land and ocean is also weakened. Therefore, the moisture transport is also weakened. For the EASM, the transportation of moisture mainly comes from two passages: from the Pacific Ocean in the east and Indian Ocean in the west.

To examine the changes in EASM circulation, the eighteen-year mean change of vertically integrated (from surface to $700 \mathrm{hPa}$ ) moisture flux and moisture flux divergence are examined for sulphate change, and is shown in Fig. 8d. Both the geographical patterns and magnitudes of changes in moisture flux divergence are consistent with changes in precipitation, suggesting that changes in the moisture transported from the adjacent oceans is the major factor contributing to precipitation decrease over East Asia. The changes of moisture flux as sulphate increases show a weakening of the EASM low level circulation. Both of the moisture transportation passages are weakened. 

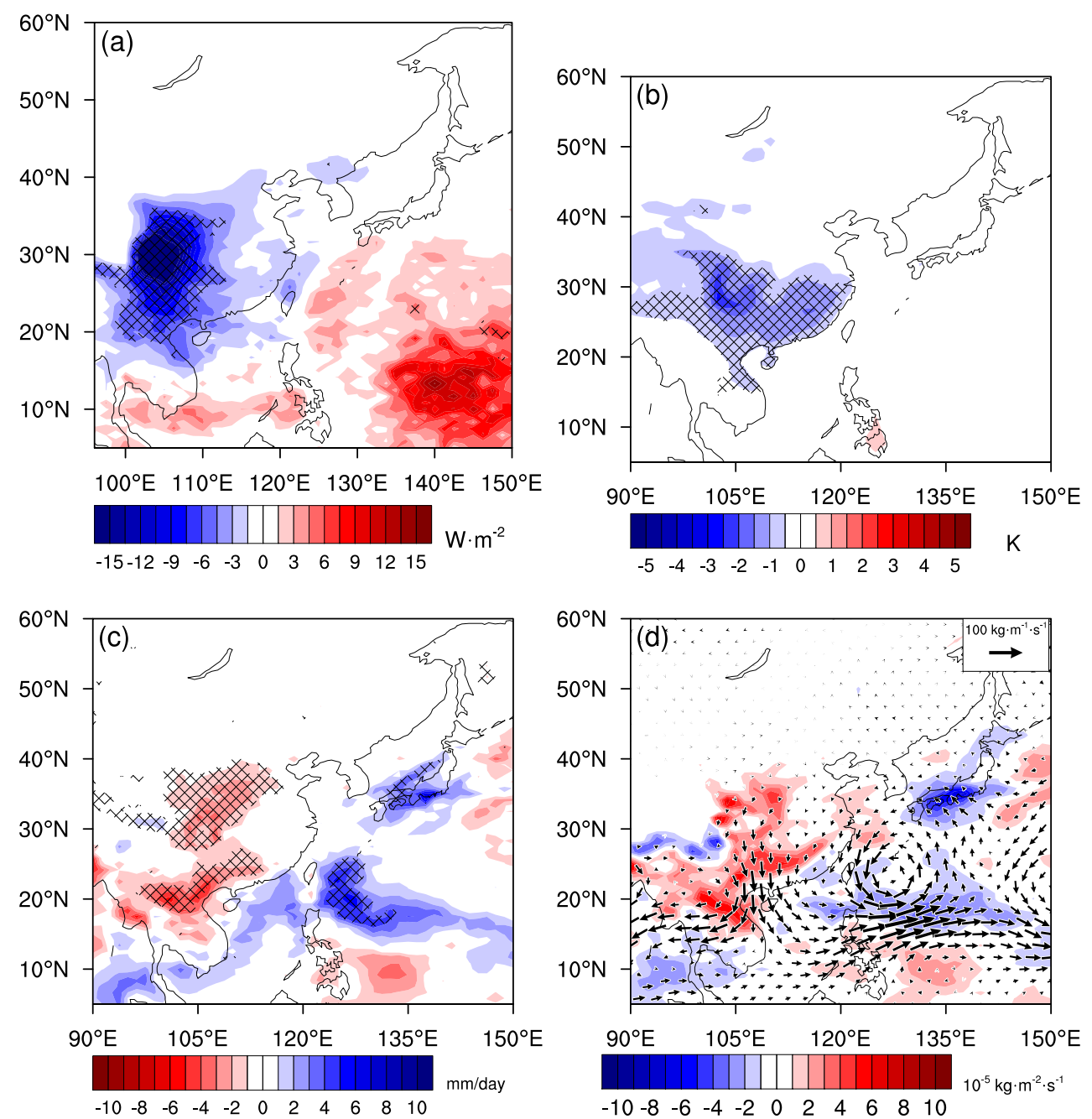

Fig. 8. (a) Eighteen-year mean net radiative flux (downward is positive) in September due to sulphate combined effect (Control minus $\mathrm{SO}_{2}$-1950). Units: $\mathrm{W} \mathrm{m}^{-2}$. The blue box indicates East Asia $\left(20-45^{\circ} \mathrm{N}, 100-122^{\circ} \mathrm{E}\right)$, the area mean value is shown above the to-right conner of the blue box. (b) Eighteen-year mean change in surface temperature in September for sulphate experiment. Units: K. (c) Eighteen-year mean change in precipitation in September for sulphate experiment. Units: $\mathrm{mm}^{-1} \mathrm{y}^{-1}$. (d) Eighteen-year mean change in vertical integrated (surface to $700 \mathrm{hPa}$ ) moisture flux (vector, Units: $\mathrm{kg} / \mathrm{m} / \mathrm{s}$ ) and moisture flux divergence (shaded, units: $\mathrm{kg} \mathrm{m}^{-2} \mathrm{~s}^{-1}$ ) for BC experiment. Significant changes excess $95 \%$ confident level are hatched.

\subsection{Black carbon experiment}

Figure $5 \mathrm{~b}$ shows monthly changes of surface temperature and precipitation due to the increase of $\mathrm{BC}$ averaged over East Asia. Unlike the responses in the sulphate experiment in which both surface temperature and precipitation consistently decrease, the sign of responses of surface temperature and precipitation in the black carbon experiment are varied. However, similar to the sulphate experiment, both surface temperature and precipitation decrease significantly in September.

The black lines in Fig. $6 \mathrm{c}$ and d show the monthly BC direct radiative effects at TOA and the surface averaged over East Asia $\left(20-45^{\circ} \mathrm{N}, 100-122^{\circ} \mathrm{E}\right)$. Unlike the sulphate di- rect radiative effect which has comparable value between TOA and the surface, the $\mathrm{BC}$ direct radiative effect has opposite signs at the TOA and surface: positive at TOA and negative at the surface. An increase in the $\mathrm{BC}$ concentration led to more solar radiation being absorbed by black carbon. As more solar radiation is absorbed, less reaches the surface, thus a negative radiative effect is shown at surface. However, the surface-atmosphere as a whole gains energy, therefore, a positive radiative effect at TOA.

The blue lines in Fig. 6c and d show the monthly BC combined effects at TOA and the surface averaged over East Asia. Since BC does not act as CCN in the model, the change of cloud droplet size is not considered in the combined effect (as shown in Fig. 4b). Even though the low cloud fraction is 


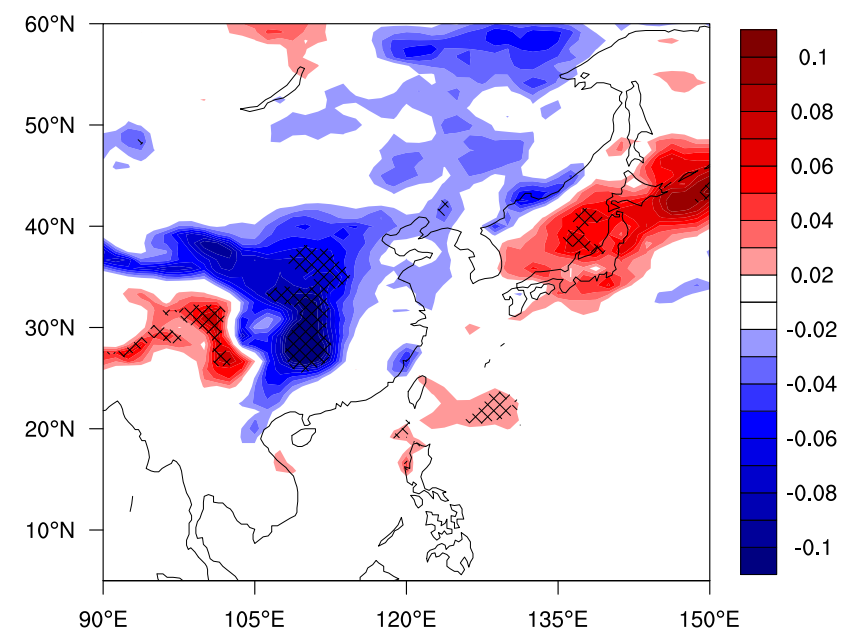

Fig. 9. Change of low cloud fraction due to black carbon changes (Control minus BC_1950) in September. Units: 1. Significant changes excess $95 \%$ confidence level are hatched.

not significantly changed in BC_1950 experiments (red line in Fig. 4c), the increases of low level cloud in September are bigger than that in Control experiment. Figure 9 shows the change of low cloud fraction due to BC changes (Control minus BC_1950) in September. The significant decrease of low level cloud is over the lee-side of the Tibetan Plateau, where the low cloud cover is building up during September. This local decrease in low cloud fraction cannot be seen when averaged over East Asia as in Fig. 4c, but it will change the BC radiative effects regionally.

Figure 10a shows the $\mathrm{BC}$ combined radiative effect in September. The $\mathrm{BC}$ direct radiative effect is compensated by a decrease in low cloud cover over the lee side of the Tibetan Plateau. This is because the increased BC concentration exerts a negative radiative effect at the surface, but as low cloud cover is reduced due to $\mathrm{BC}$ heating, more solar radiation reaches the surface which partially compensates for the $\mathrm{BC}$ direct radiative effect. In the additional off-line simulation changing only cloud properties (see Fig. S14), the changes in low-cloud offset $1.2 \mathrm{Wm}^{-2}$ radiative flux at the surface and this accounts for $30 \%$ of the $\mathrm{BC}$ direct radiative effect. Comparing the sulphate combined radiative effect to the $\mathrm{BC}$ combined radiative effect at the surface, the patterns are different, and the responses of the EASM are also different.

Figure 10b shows the eighteen-year mean changes of surface temperature in September in the BC experiment. Compared to the sulphate experiment, the extent of the surface temperature decrease is smaller; it is only significant over south-eastern China and parts of central China; the magnitude is also smaller. Figure 10c shows the eighteen-year mean changes of precipitation in September in the BC experiment. The decrease of precipitation in the $\mathrm{BC}$ experiment is weaker, and is mainly over central China. Figure 10d shows the eighteen-year mean change of vertically integrated (from surface to $700 \mathrm{hPa}$ ) moisture flux and moisture flux divergence in September in the BC experiment. In comparison with the sulphate experiment, only the eastern passage of moisture transport is weakened. Thus the weakening of the EASM circulation is less in the BC experiment, and the reduction in precipitation is less when compared to the sulphate experiment. As the low cloud cover decrease compensates the $\mathrm{BC}$ direct radiative effect, the temperature is changed less over the lee side of the Tibetan Plateau and the Indochina Peninsula than in sulphate experiment. The change in landsea surface temperature contrast with the Indian Ocean is not as strong as the change further east with the Pacific Ocean, thus only the eastern moisture transport route is affected.

\section{Conclusions and discussions}

In this study, experiments using HiGAM with an interactive aerosol scheme show that the EASM in the model is altered when local emissions of either sulphate and black carbon aerosols are increased from 1950 to 2000 levels. Compared with previous studies, the intra-seasonal variation in monsoon features as a result of the aerosol changes has been looked at in more detail.It is found that the impacts of aerosols are more significant during the withdrawal phase of the EASM (September) rather than active phase (JJA). We also evaluated separately the direct, indirect and semi-direct effects of aerosol thus this study is able to highlight the different mechanisms responsible for change in EASM depending on the type of aerosol considered.

For sulphates:

- The direct radiative effect cools the surface but not enough to alter the EASM.

- The indirect radiative effect on cloud droplet size is large in September due to the vertical coincidence of aerosol and low level cloud.

- The cloud albedo is increased and the surface temperature cools over a wide region of East Asia.

- The decrease in land-sea thermal contrast weakens the circulation, transporting less moisture from both ocean basins.

For black carbon:

- The direct radiative effect is the major factor contributing to changes in EASM in September.

- Low level cloud cover decreases as the absorption of solar radiation by $\mathrm{BC}$ heats the atmosphere.

- The direct radiative effect is regionally compensated by decreased low level cloud over Sichuan basin as more solar radiation reaches the surface (From $-3.2 \mathrm{Wm}^{-2}$ to $-2.9 \mathrm{Wm}^{-2}$ ). 

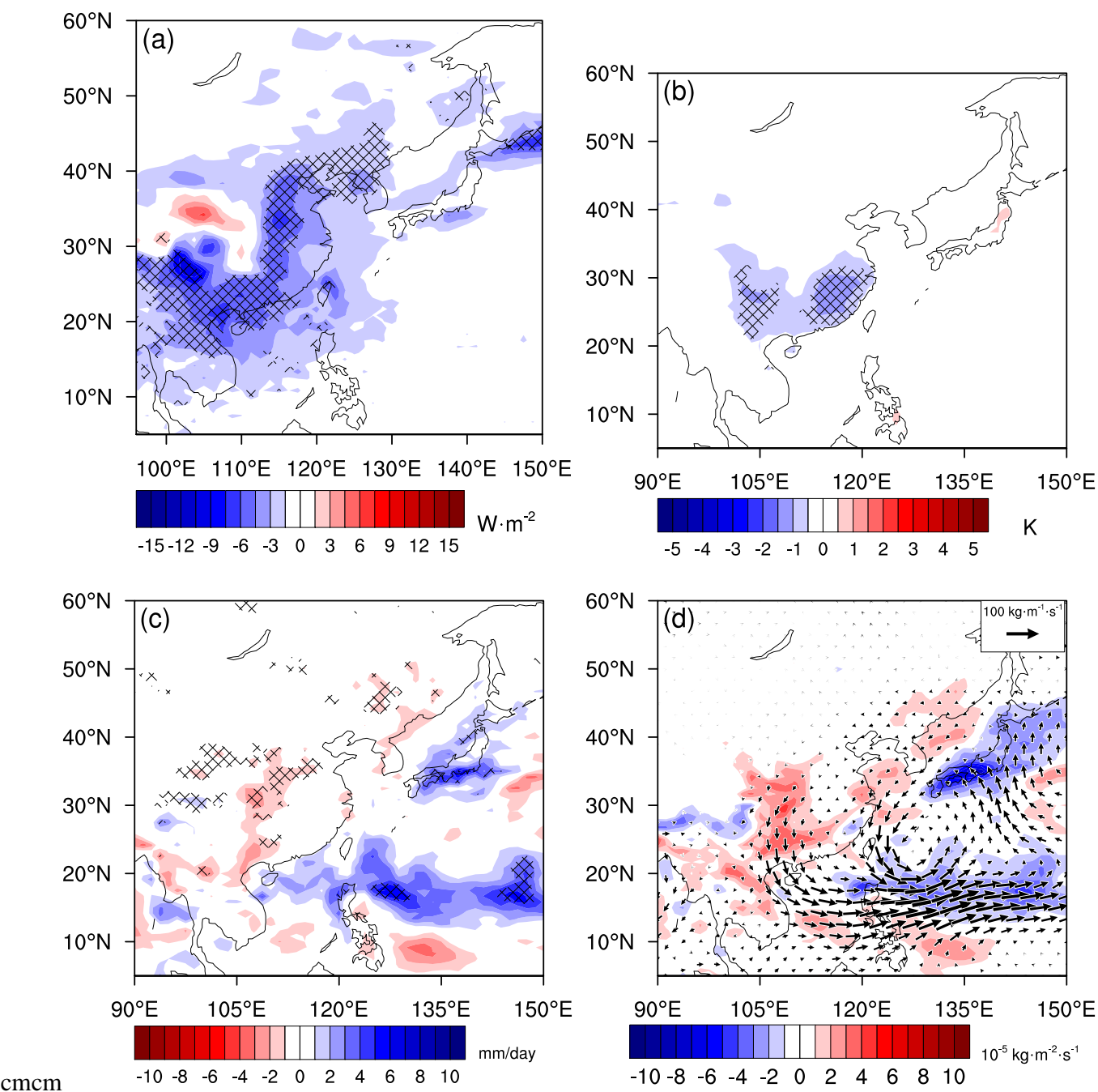

Fig. 10. (a) Eighteen-year mean net radiative flux (downward is positive) in September due to BC combined effect (Control minus BC_1950). Units: $\mathrm{W} \mathrm{m}^{-2}$. The blue box indicates East Asia $\left(20-45^{\circ} \mathrm{N}, 100-122^{\circ} \mathrm{E}\right)$, the area mean value is shown above the to-right conner of the blue box. (b) Eighteen-year mean change in surface temperature in September for BC experiment. Units: K. (c) Eighteen-year mean change in precipitation in September for BC experiment. Units: $\mathrm{mm} /$ day. (d) Eighteen-year mean change in vertical integrated (surface to $700 \mathrm{hPa}$ ) moisture flux (vector, units: $\mathrm{kg} \mathrm{m}^{-1} \mathrm{~s}^{-1}$ ) and moisture flux divergence (shaded, units: $\mathrm{kg} \mathrm{m}^{-2} \mathrm{~s}^{-1}$ ) for BC experiment. Significant changes excess $95 \%$ confident level are hatched.

- The decrease in land surface temperature is mainly over southeastern China, and compared to the sulphate experiment, the weakening of moisture transport exists only from Pacific Ocean.

How robust is this study? The atmospheric GCM means that the aerosol impact on SST and feedbacks of SST changes in aerosols have not been considered. However, the likely SST change can be estimated using averaged aerosol radiative effect at the surface and averaged ocean mixed layer depth, as $\Delta \mathrm{SST}=\frac{1}{\rho c_{\mathrm{p}}} \frac{\Delta F}{\Delta z} \Delta t . \Delta \mathrm{SST}$ is change of SST in $\Delta t$ of time, $\rho$ is density of sea water. $c_{\mathrm{p}}$ is constant-pressure heat capacity of sea water. $\Delta F$ is changes of the net radiation reaching the surface over the ocean as calculated in off-line E-S code (as shown in Fig. 8a). $\Delta z$ is the depth of the averaged ocean mixing layer. The estimated SST changes indicate that the change in SST caused by aerosol is not significantly greater than internal variation of SST, which is about $0.6 \mathrm{~K} \mathrm{month}^{-1}$.

If the internal mixing rather than the external mixing of aerosol were considered, the response of EASM may be different since the contributions from direct and indirect aerosol effects are different. For example, the direct effects from both sulphate and BC will decrease (Lesins et al., 2002), and, since $\mathrm{BC}$ can become coated with sulphate to act as $\mathrm{CCN}$, the indirect effect considering cloud droplet size change could be stronger. Additionally, mineral dust may also affect the EASM. However, the impact of dust is not included in this study as anthropogenic aerosols are the main focus, and 
trends in dust over the same period are not clear (Lee and Sohn, 2011).

Despite limitations, this study is the first to consider impact of local emissions of aerosol on EASM. The results suggest that changes in aerosol and the subsequent changes in cloud can affect the monsoon circulation and precipitation. Given the hypothesised reduction in aerosol emissions by 2100 according to latest emission scenarios from IPCC CMIP5 (e.g., van Vuuren et al., 2007; Fujino et al., 2006), this study is relevant to predicting future changes in the East Asian Summer Monsoon.

\section{Supplementary material related to this article is available online at: http://www.atmos-chem-phys.net/13/ 1521/2013/acp-13-1521-2013-supplement.pdf.}

Acknowledgements. LG was supported by a departmental fellowship of the University of Reading. LCS was funded by the National Centre for Atmosphere Science-Climate division, a NERC collaborative centre. AGT was funded by a NERC Fellowship reference NE/HO15655/1. We are grateful to Margaret Woodage of ESSC for providing control run configuration and start dumps and for many helpful discussions. The high performance computing facilities were provided by HECToR.

Edited by: J. Quaas

\section{References}

Adler, R., Huffman, G., Chang, A., Ferraro, R., Xie, P., Janowiak, J., Rudolf, B., Schneider, U., Curtis, S., Bolvin, D., Gruber, A., Susskind, J., Arkin, P., and Nelkin, E.: The Version-2 Global Precipitation Climatology Project(GPCP) Monthly Precipitation Analysis(1979-Present), J. Hydrometeorol., 4, 1147-1167, 2003.

Albrecht, B.: Aerosols, cloud microphysics, and fractional cloudiness, Science, 245, 1227, 1989.

Ashrit, R., Douville, H., and Kumar, K.: Response of the Indian monsoon and ENSO-monsoon teleconnection to enhanced greenhouse effect in the CNRM coupled model, J. Meteor. Soc. Jpn., 81, 779-803, 2003.

Boer, G. and Yu, B.: Climate sensitivity and response, Clim. Dynam., 20, 415-429, 2003.

Boucher, O., Pham, M., and Sadourny, R.: General circulation model simulations of the Indian summer monsoon with increasing levels of sulphate aerosols, ANGEO, 16, 346-352, 1998.

Chung, C. and Ramanathan, V.: Weakening of North Indian SST gradients and the monsoon rainfall in India and the Sahel, J. Climate, 19, 2036-2045, 2006.

Chung, C. and Zhang, G.: Impact of absorbing aerosol on precipitation: Dynamic aspects in association with convective available potential energy and convective parameterization closure and dependence on aerosol heating profile, J. Geophys. Res., 109, D22103, doi:10.1029/2004JD004726, 2004.

Collins, W., Stevenson, D., Johnson, C., and Derwent, R.: Tropospheric ozone in a global-scale three-dimensional Lagrangian model and its response to NOX emission controls, J. Atmos. Chem., 26, 223-274, 1997.

Davies, T., Cullen, M., Malcolm, A., Mawson, M., Staniforth, A., White, A., and Wood, N.: A new dynamical core for the Met Office's global and regional modelling of the atmosphere, Q. J. Roy. Meteor. Soc., 131, 1759-1782, 2005.

Edwards, J. and Slingo, A.: Studies with a flexible new radiation code. I: Choosing a configuration for a large-scale model, Q. J. Roy. Meteor. Soc., 122, 689-719, 1996.

Forster, P., Ramaswamy, V., Artaxo, P., Berntsen, T., Betts, R., Fahey, D., Haywood, J., Lean, J., Lowe, D., Myhre, G., Nganga, J., Prinn, R., Raga, G., Schulz, M., and Van Dorland, R.: Climate Change 2007: The Physical Science Basis. Contribution of Working Group I to the Fourth Assessment Report of the Intergovernmental Panel on Climate Change, chap. Changes in Atmospheric Constituents and in Radiative Forcing, Cambridge University Press, Cambridge, UK and New York, NY, USA, 2007.

Fujino, J., Nair, R., Kainuma, M., Masui, T., and Matsuoka, Y.: Multi-gas mitigation analysis on stabilization scenarios using AIM global model, Multigas Mitigation and Climate Policy, Special Issue 3, 343, 2006.

Gates, W., Boyle, J., Covey, C., Dease, C., Doutriaux, C., Drach, R., Fiorino, M., Gleckler, P., Hnilo, J., Marlais, S., Phillips, T., Potter, G., Santer, B., Sperber, K., Taylor, K., and Williams, D.: An overview of the results of the Atmospheric Model Intercomparison Project (AMIP I), B. Am. Meteorol. Soc., 80, 29-56, 1999.

Gregory, D. and Rowntree, P.: A Mass Flux Convection Scheme With Representation Of Cloud Ensemble Characteristics And Stability-Dependent Closure, Mon. Weather Rev., 118, 14831506, 1990.

Haywood, J. and Boucher, O.: Estimates of the direct and indirect radiative forcing due to tropospheric aerosols: A review, Rev. Geophys., 38, 513-543, 2000.

Haywood, J. and Shine, K.: Multi-spectral calculations of the direct radiative forcing of tropospheric sulphate and soot aerosols using a column model, Q. J. Roy. Meteor. Soc., 123, 1907-1930, 1997.

Huang, Y., Chameides, W., and Dickinson, R.: Direct and indirect effects of anthropogenic aerosols on regional precipitation over east Asia, J. Geophys. Res., 112, D03212, doi:10.1029/2006JD007114, 2007.

Hung, C., Liu, X., and Yanai, M.: Symmetry and asymmetry of the Asian and Australian summer monsoons, J. Climate, 17, 24132426, 2004.

Iwasaki, T. and Kitagawa, H.: A possible link of aerosol and cloud radiations to Asian summer monsoon and its implication in longrange numerical weather prediction, J. Meteor. Soc. Jpn., 76, 965-982, 1998.

Johns, T., Gregory, J., Ingram, W., Johnson, C., Jones, A., Lowe, J., Mitchell, J., Roberts, D., Sexton, D., Stevenson, D., Tett, S., and Woodage, M.: Anthropogenic climate change for 1860 to 2100 simulated with the HadCM3 model under updated emissions scenarios, Clim. Dyn., 20, 583-612, 2003.

Jones, A., Roberts, D., Woodage, M., and Johnson, C.: Indirect sulphate aerosol forcing in a climate model with an interactive sulphur cycle, J. Geophys. Res., 106, 20293-20310, 2001.

Kim, M., Lau, W., Kim, K., and Lee, W.: A GCM study of effects of radiative forcing of sulfate aerosol on large scale circulation and rainfall in East Asia during boreal spring, Geophys. Res. Lett., 34, L24701, doi:10.1029/2007GL031683, 2007. 
Lau, K., Kim, M., and Kim, K.: Asian summer monsoon anomalies induced by aerosol direct forcing: the role of the Tibetan Plateau, Clim. Dynam., 26, 855-864, 2006.

Lee, E. and Sohn, B.: Recent increasing trend in dust frequency over Mongolia and Inner Mongolia regions and its association with climate and surface condition change, Atmos. Environ., 45, 4611-4616, 2011.

Lesins, G., Chylek, P., and Lohmann, U.: A study of internal and external mixing scenarios and its effect on aerosol optical properties and direct radiative forcing, J. Geophys. Res., 107, 4094, doi:10.1029/2001JD000973, 2002.

Martin, G., Ringer, M., Pope, V., Jones, A., Dearden, C., and Hinton, T.: The physical properties of the atmosphere in the new Hadley Centre Global Environmental Model (HadGEM1). Part I: Model description and global climatology, J. Climate, 19, 12741301, 2006.

Meehl, G., Arblaster, J., and Collins, W.: Effects of black carbon aerosols on the Indian monsoon, J. Climate, 21, 2869-2882, 2008.

Menon, S., Hansen, J., Nazarenko, L., and Luo, Y.: Climate effects of black carbon aerosols in China and India, Science, 297, 2250, 2002.

Ming, Y., Ramaswamy, V., and Persad, G.: Two opposing effects of absorbing aerosols on global-mean precipitation, Geophys. Res. Lett., 37, L13701, doi:10.1029/2010GL042895, 2010.

Myhre, G., Jonson, J., Bartnicki, J., Stordal, F., and Shine, K.: Role of spatial and temporal variations in the computation of radiative forcing due to sulphate aerosols: A regional study, Q. J. Roy. Meteor. Soc., 128, 973-989, 2002.

Nozawa, T., Nagashima, T., Ogura, T., Yokohata, T., Okada, N., and Shiogama, H.: Climate change simulations with a coupled oceanatmosphere GCM called the model for interdisciplinary research on climate: MIROC, Tech. Rep. Vol. 12, Center for Global Environmental Research, National Institute for Environmental Studies, Japan, 2007.

Ramanathan, V., Crutzen, P., Lelieveld, J., Mitra, A., Althausen, D., Anderson, J., Andreae, M., Cantrell, W., Cass, G., Chung, C., Clarke, A., Coakley, J., Collins, W., Conant, W., Dulac, F., Heintzenberg, J., Heymsfield, A., Holben, B., Howell, S., Hudson, J., Jayaraman, A., Kiehl, J., Krishnamuri, T., Lubin, D., McFarquhar, G., Novakov, T., Ogren, J., Podgorny, J., Prather, K., Pristley, K., Prospero, J., Quinn, P., Rajeev, K., Rasch, P., Rupert, S., Sadourny, R., SK, S., GE, S., Sheridan, P., and Vatero, F.: Indian Ocean Experiment: An integrated analysis of the climate forcing and effects of the great Indo-Asian haze, J. Geophys. Res., 106, 28371-28398, doi:10.1029/2001JD900133, 2001.

Ramanathan, V., Chung, C., Kim, D., Bettge, T., Buja, L., Kiehl, J., Washington, W., Fu, Q., Sikka, D., and Wild, M.: Atmospheric brown clouds: Impacts on South Asian climate and hydrological cycle, Proc. Natl. Acad. Sci. USA, 102, 5326, 2005.

Randles, C. and Ramaswamy, V.: Absorbing aerosols over Asia: A Geophysical Fluid Dynamics Laboratory general circulation model sensitivity study of model response to aerosol optical depth and aerosol absorption, J. Geophys. Res., 113, D21203, doi:10.1029/2008JD010140, 2008.

Roberts, D. and Jones, A.: Climate sensitivity to black carbon aerosol from fossil fuel combustion, J. Geophys. Res., 109, D16202, doi:10.1029/2004JD004676, 2004.
Roeckner, E., Bengtsson, L., Feichter, J., Lelieveld, J., and Rodhe, H.: Transient climate change simulations with a coupled atmosphere-ocean GCM including the tropospheric sulfur cycle, J. Climate, 12, 3004-3032, 1999.

Shaffrey, L., Stevens, I., Norton, W., Roberts, M., Vidale, P., Harle, J., Jrrar, A., Stevens, D., Woodage, M., Demory, M., Donners, J., Clark, D., Clayton, A., Cole, J., Wilson, S., Connolleg, W., Davies, T., Iwi, A., Johns, T., King, J., New, A., Slingo, J., Slingo, A., Steenman-Clark, L., and Martin, G.: UK HiGEM: the new UK high-resolution global environment model-model description and basic evaluation, J. Climate, 22, 1861-1896, 2009.

Smith, R.: A Scheme For Predicting Layer Clouds And Their WaterContent In A General-Circulation Model, Quarterly Journal Of The Royal Meteorological Society, 116, 435-460, 1990.

Smith, S., Andes, R., Conception, E., and Lurz, J.: Historical sulfur dioxide emissions, 1850-2000: methods and results, Tech. Rep. 14537, Pacific Northwest National Laboratory, Joint Global Change Research Institute 8400 Baltimore Avenue College Park, Maryland 20740, 2004.

Sperber, K. R., Annamalai, H., Kang, I.-S., Kitoh, A., Moise, A., Turner, A., Wang, B., and Zhou, T.: The Asian Summer Monsoon: An Intercomparison of CMIP5 vs. CMIP3 Simulations of the Late 20th Century, Clim. Dynam., 1-34, 2012.

Stevenson, D., Collins, W., Johnson, C., and Derwent, R.: The impact of aircraft nitrogen oxide emissions on tropospheric ozone studied with a 3D Lagrangian model including fully diurnal chemistry, Atmos. Environ., 31, 1837-1850, 1997.

Tian, S. and Yasunari, T.: Time and space structure of interannual variations in summer rainfall over China, J. Meteor. Soc. Jpn., 70, 585-596, 1992.

Trenberth, K., Stepaniak, D., and Caron, J.: Global monsoon as seen through the divergent atmospheric circulation, J. Climate, 13, 3969-3993, 2000.

Twomey, S.: The influence of pollution on the shortwave albedo of clouds, J. Atmos. Sci., 34, 1149-1152, 1977.

Uppala, S., Kållberg, P., Simmons, A., Andrae, U., Bechtold, V., Fiorino, M., Gibson, J., Haseler, J., Hernandez, A., Kelly, G., et al.: The ERA-40 re-analysis, Q. J. Roy. Meteor. Soc., 131, 2961-3012, 2005.

van Vuuren, D. P., Den Elzen, M. G. J., Lucas, P. L., Eickhout, B., Strengers, B. J., van Ruijven, B., Wonink, S., and van Houdt, R.: Stabilizing greenhouse gas concentrations at low levels: an assessment of reduction strategies and costs, Clim. Change, 81, 119-159, 2007.

Wang, B. and Ding, Q.: Changes in global monsoon precipitation over the past 56 years, Geophys. Res. Lett., 33, L06711, doi:10.1029/2005GL025347, 2006.

Wang, C.: Impact of direct radiative forcing of black carbon aerosols on tropical convective precipitation, Geophys. Res. Lett., 34, L05709, doi:10.1029/2006GL028416, 2007.

Woodage, M., Davison, P., and Roberts, D.: Aerosol processes, Tech. Rep. 20, Met Office, 2003.

Yu, R., Wang, B., and Zhou, T.: Climate effects of the deep continental stratus clouds generated by the Tibetan Plateau, J. Climate, 17, 2702-2713, 2004.

Zhai, P., Zhang, X., Wan, H., and Pan, X.: Trends in total precipitation and frequency of daily precipitation extremes over China, J. Climate, 18, 1096-1108, 2005. 